\title{
Hydrothermal Alteration of Cambro-Ordovician Carbonates of North America: Lessons for the Paleozoic Carbonates of SE Asia.
}

Richard D.Bray(brayrd@yahoo.com)

Adriaan Bal (Adriaan.Bal@ BakerHughes.com)

Hydrothermal reservoirs and the related Mississippi Valley-Type mineral deposits (MVT) display a broad distribution in time and space, but are most abundant and prolific in North America. Hydrothermal alteration often is not recognized, distinguished, or even considered in the hydrocarbon provinces worldwide. With the exception of Nang Nuan, hydrothermal reservoirs are unreported in the Paleozoic (and younger) rocks of SE Asia. This is perhaps due to failure to appreciate and distinguish hydrothermal fabrics.

In this presentation, core and outcrop studies of carbonate rocks in North American identify discrete intervals of hydrothermal alteration with unique petrologic, petrographic and geochemical signatures. Hydrothermal alteration often overprints on karst templates, thus obscuring the precise origins of the observed fabrics. These North American examples provide an analogue for similar features that are evident in the Paleozoic rocks of Thailand.

The Paleozoic Ratburi carbonates of the Nang Nuan Field, Gulf of Thailand, provide salient lessons regarding the construction and application of geologic models. The Nang Nuan carbonate reservoirs, display features, initially believed to be due to subaerial exposure and meteoric diagenesis, but subsequently shown to be due to hydrothermal processes. Adherence to improper or insufficient analogues will provide incorrect estimates of hydrocarbons in place, prospect ranking and risking. 